\title{
A Five-year retrospective hospital-based study on epidemiological data regarding human Leishmaniasis in West Kordofan state - Sudan
}

\section{Abdullah, A. A ( $\square$ bahlol32029@gmail.com)}

Department of Biomedical Sciences, Faculty of Veterinary Sciences, University of Gadarif, Gadarif state, Sudan and Department of Reproductive Health Sciences, Pan African University Life and Earth Sciences Institute (PAULESI), University of Ibadan, Ibadan, Nigeria https://orcid.org/0000-0003-2534-4953

\section{Musa AHMED}

Department of Veterinary Surgery, Faculty of Veterinary Medicine, AL-Salam University, West Kordofan state, Afula, Sudan and Department of Reproductive Health Sciences, Pan African University Life and Earth Sciences Institute (PAULESI), University of Ibadan, Ibadan, Nigeria https://orcid.org/0000-00030224-9718

\section{Ahmed GADEED}

Environmental Studies and Research Center, Al-Salam University, West Kordofan state, Afula, Sudan.

\section{Adam Eltayeb}

Al-Sadaga hospital, West Kordofan state, Afula, Sudan.

\section{Safa AHMED}

Al-Sadaga hospital, West Kordofan state, Afula, Sudan.

\section{Suad HAMAD}

Department of Zoonotic disease and Disease control, Ministry of Animal Resources, South Kordofan state, Al-Hamadi, Sudan.

\section{Mohammed Hussein}

Department of Statistics and Health Information Ministry of Health, West Kordofan state, Afula, Sudan.

\section{Research Article}

Keywords: Epidemiology, Human Leishmaniasis, West Kordofan, Sudan

Posted Date: December 29th, 2021

DOI: https://doi.org/10.21203/rs.3.rs-1201676/v1

License: (9) This work is licensed under a Creative Commons Attribution 4.0 International License. Read Full License 


\section{Abstract \\ Background}

Leishmaniasis is a parasitic zoonotic disease caused by the Leishmania parasites genus. The estimation of this disease is very important to inform the health care policymakers and the governments to applied proper health and economic policies. Thus, this study aimed, to find out the frequency and distribution of human leishmaniasis in West Kordofan state, based on sex and age during 5 years- Sudan.

\section{Methods}

Five years retrospective study from 2016 through 2020 was carried out using local hospital records of leishmaniasis patients. The age and gender of each patient were recorded. The collected data were analysed using STATA package version 16.

\section{Results}

A total of 162,443 patient records from 2016 to 2020 were retrieved. Of these, $4.39 \%$ were found to be positive for leishmaniasis. The disease has been more common in males $(65.3 \%)$ than in females (, $34.7 \%)$. The highest reported prevalence (6.58\%) was in patients $15-44$ years old, which was, and the lowest prevalence $(1.95 \%)$ was among patients in $\geq 65$-year-old.

\section{Conclusion}

The current study indicates that leishmaniasis is endemic in the study area even though the numbers of patients in the five consecutive years were varying. Besides, the disease was common in males and adults.

\section{Introduction}

Leishmaniasis is a parasitic zoonotic disease caused by the Leishmania parasites genus (1). The disease is mainly transmitted by the bite of infected female phlebotomine sandflies (2). World health organizations (WHO) classified the disease as a neglected tropical disease (NTD) $(2,3)$. There are several different forms of human leishmaniasis, and the most common forms are cutaneous leishmaniasis (CL), which causes skin sores, and visceral leishmaniasis (VL), which affects several internal organs (usually spleen, liver, and bone marrow)(4). All forms of the disease have been strongly associated with poor socioeconomic status, population displacement, a weak immune system, and climate change(5-8). Leishmaniasis cases have been reported in almost all continents in about 89 countries, with an estimated 700000 to 1 million new cases occur annually. Most cases occur in East Africa, Southeast Asia, and 
South America $(4,9)$. Human leishmaniasis outbreaks reported worldwide were from East African countries namely Sudan, South Sudan, and Ethiopia (10-15).

Sudan is a highly leishmaniasis endemic country (both $C L$ and $V L$ ). The disease represents a serious health problem that may affect the whole healthcare system(16). The geographical distributions of the disease in Sudan have high relations to the distribution of the vectors. studies revealed that VL is endemic in the savannah area which starts from Gadarif state in the east to the White Nile State in the west, and from Kassala state in the northeast to the Blue Nile State in the south. Also, VL was reported in some scattered foci in the Kordofan states and Darfur states. Moreover, $\mathrm{CL}$ is found in a fluctuating pattern mainly in the northern, central, and western parts of the country(17-26).

West Kordofan is the 18th state of Sudan, it was established in July 2013 on the border with the Republic of South Sudan in the east, North Kordofan State in the North, South Darfur State in the west. People of West Kordofan especially the Mesairya tribe continuously moving to and from South Sudan where leishmaniasis disease is endemic(7). The state also, containing many south Sudanese refugees' camps spread almost all over the state. The geographical location together with the high presence of the suspected infected refugees makes the people of West Kordofan state are very vulnerable to leishmaniasis for both CL and VL. A community-based study in two West Kordofan cities, namely Muglad and Babnousa, reported that out of 1781 randomly selected volunteers, 238 persons (13\%) tested positive for leishmaniasis(27). Based on that, there is still a need for a deeper look at the epidemiology of the disease in the whole state, in both males and females and all ages groups, to design and imply suitable prevention and eradication programs for the disease at the state level. Thus, this study aimed to find out the frequency and distribution of human leishmaniasis in West Kordofan state, based on sex and age during 5 years.

\section{Materials And Methods}

The present retrospective study was conducted among patients who were admitted to any hospital in West Kordofan state -Sudan from the 1st January 2016 to the 31st of December 2020. Data of age, gender, and presence of any type of leishmaniasis were retrieved from the medical records department in the ministry of health west Kordofan, with the approval of the ministry ethical committee. The medical record department follows the guidelines of the International Classification of Diseases (ICD)-10 coding.

\subsection{Statistical analysis}

Descriptive statistics and data analysis were done using STATA package version 16 (Stata Corp LLC, College Station, TX). Z test was applied to compare the proportions between the study groups and if the P-value was less than or equal to 0.05 indicates that there was a significant difference between the proportions of the two groups.

\section{Results}


A total of 162,443 patient records ( 87847 females and 74596 males patients) from 2016 to 2020 were retrieved. Of these, $4.39 \%$ were found to be positive for leishmaniasis, $34.7 \%$ were female and $65.3 \%$ were males. The diagnostic prevalence of the infection was first founded to be very low in 2016 (2.57\%), and just after one year in 2017 turned to become the highest reported prevalence at $5.83 \%$ and then start to decreased (with some fluctuation) to $3.67 \%$ in 2020 (Figure 1).

Gender-related differences in leishmaniasis prevalence are presented in Table (1), and the prevalence was significantly higher $(P \leq 0.05)$ in males compared to females in the period from 2017 to 2020 , while in 2016 , it didn't show any significant variation with the $\operatorname{sex}(P>0.05)$.

The prevalence of leishmaniasis was relatively increased with participant age in both females and males. The prevalence reached its peak in patients with $15-44$ years old, which was $6.58 \%$, then decreased to be the lowest limit of $1.95 \%$ among patients in $\geq 65$-year-old (Table. $2 \& 3$ ).

In addition to that in all age groups, males had a higher prevalence of leishmaniasis than females.

\section{Discussion}

Leishmaniasis is an endemic neglected zoonotic disease in Sudan, widespread all over the country from the eastern states to the western states, and from southern states to northern states (16). However, a few data about the epidemiological and demographical distribution of the disease in western states is available in general and especially in west Kordofan, and it seems to be overlooked $(20,24,25,27)$, thus the current study is the first comprehensive attempt to describe the epidemiological and demographical distribution of the disease in the state.

In this study, the data of human leishmaniasis was collected from the annual health statistical reports for 5 years (2016-2020) and analyzed to show the burden of the disease in West Kordofan State, Sudan.

The results highlight that a total of 162,443 people were admitted to the hospitals and health care centers in the state. Of these, 7,128 people were infected during this period. In 2016 the prevalence of leishmaniasis was found to be very low at $2.57 \%$, surprisingly it was raised to $5.83 \%$ in 2017 , and from then it seemed to decrease. The reason could be mainly since the government of Sudan in October 2014 with collaboration with $\mathrm{WHO}$ and other related international organizations, has developed diagnostic and control strategies to limit the spread of the disease $(28,29)$. The first two years 2015 and 2016 were for training the health care professional in the state, on the new diagnostic and prevention methods. That may explain the low prevalence in the first study year because of the use of the low sensitivity diagnostic test, and then after implying the new diagnostic method in 2017 it raised. In line with that after 2017, the prevalence of leishmaniasis is decreasing because of implying the new control strategies.

The current study found that the overall prevalence of leishmaniasis in West Kordofan was lower than that reported by Sharief et al(27) in 2019, this may be due to the difference in sample size and study period which both were bigger and longer respectively in the current study compared with the other study. 
Nevertheless, the study area could have a great impact on the result, In their study, Sharief et al (27) were just applied in two districts in the state but the current study collected data from all 14th districts.

Sex-related distribution of human leishmaniasis in the study revealed that males were highly affected compared to females with an overall percentage of $65.3 \%$ and $34.7 \%$ respectively. This is in line with Ali 2007(30), Ebrahim 2016(25), and Collis et al 2019 (31), and disagrees with Mohammed et al 2018(20). This result might be justified because the majority of males are nomads and they are moving seasonally to the tropic and subtropic areas in South Sudan whereby the exposure to the risk of sandflies bites is high, as well as the same exposure of the males to different agricultural areas may be a contributing factor to the infections. Consequently, males are more vulnerable than females.

Age-wise distribution found that people of age group 15-44 had the highest prevalence among all populations similar results were reported by Ali 2007(30), Osman 2011(24), Ebrahim 2016(25), and Collis et al 2019(31), whose indicated that the adult men and women who aged between (15-44 years) were more affected by the disease compared to the lower and higher age groups. This can be put in the context that this age group is the working-age group in all fields, especially the agricultural field. In contracts that a study conducted by Mohammed et al 2018(20) indicated that the most affected age groups were children between 1 and 5 years old.

\section{Conclusions}

The current study indicates that leishmaniasis is endemic in the study area even though the numbers of patients in the five consecutive years were varying. Besides, the disease was common in males and adults.

\section{Declarations}

\section{Acknowledgements}

None.

\section{Ethical Considerations}

Individual consent was not required as the data used were secondary, collected from the Ministry of health west Kordofan data center. Ethical approval and permission were obtained from Ministry of health west Kordofan Ethics Review Committee.

\section{Competing interests}

The authors declare that they have no competing interests.

\section{Availability of data and materials}


The data that support the findings of this study are available at the Ministry of health west Kordofan but restrictions apply to the availability of these data, which were used under license for the current study, and are not publicly available. Data are however available from the authors upon reasonable request and with the permission of the Ministry of health west Kordofan.

\section{Funding}

None.

\section{References}

1. Torres-Guerrero E, Quintanilla-Cedillo MR, Ruiz-Esmenjaud J, Arenas R. Leishmaniasis: a review. F1000Res. 2017;6:750.

2. Elaagip A, Ahmed A, Wilson MD, Boakye DA, Abdel Hamid MM. Studies of host preferences of wildcaught Phlebotomus orientalis and Ph. papatasi vectors of leishmaniasis in Sudan. PLoS One. 2020;15(7):e0236253.

3. WHO. Control of Neglected Tropical Diseases 2021 [cited 2021 03/08/2021]. Available from: https://www.who.int/teams/control-of-neglected-tropical-diseases.

4. WHO. Leishmaniasis 2021 [cited 2021 03/08/2021]. Available from: https://www.who.int/newsroom/fact-sheets/detail/leishmaniasis.

5. Alvar J, Yactayo S, Bern C. Leishmaniasis and poverty. Trends Parasitol. 2006;22(12):552-7.

6. Shirzadi MR, Javanbakht M, Vatandoost H, Jesri N, Saghafipour A, Fouladi-Fard R, et al. Impact of Environmental and Climate Factors on Spatial Distribution of Cutaneous Leishmaniasis in Northeastern Iran: Utilizing Remote Sensing. J Arthropod Borne Dis. 2020;14(1):56-67.

7. Al-Salem W, Herricks JR, Hotez PJ. A review of visceral leishmaniasis during the conflict in South Sudan and the consequences for East African countries. Parasit Vectors. 2016;9(1):460.

8. Diro E, Lynen L, Ritmeijer K, Boelaert M, Hailu A, van Griensven J. Visceral Leishmaniasis and HIV coinfection in East Africa. PLoS Negl Trop Dis. 2014;8(6):e2869.

9. Alvar J, Velez ID, Bern C, Herrero M, Desjeux P, Cano J, et al. Leishmaniasis worldwide and global estimates of its incidence. PLoS One. 2012;7(5):e35671.

10. Seaman J, Pryce D, Sondorp HE, Moody A, Bryceson AD, Davidson RN. Epidemic visceral leishmaniasis in Sudan: a randomized trial of aminosidine plus sodium stibogluconate versus sodium stibogluconate alone. J Infect Dis. 1993;168(3):715-20. 
11. Seaman J, Mercer AJ, Sondorp E. The epidemic of visceral leishmaniasis in western Upper Nile, southern Sudan: course and impact from 1984 to 1994. Int J Epidemiol. 1996;25(4):862-71.

12. Ashford RW, Seaman J, Schorscher J, Pratlong F. Epidemic visceral leishmaniasis in southern Sudan: identity and systematic position of the parasites from patients and vectors. Trans R Soc Trop Med Hyg. 1992;86(4):379-80.

13. Perea WA, Moren A, Ancelle T, Sondorp E. Epidemic visceral leishmaniasis in southern Sudan. Lancet. 1989;2(8673):1222-3.

14. Gebre-Michael T, Balkew M, Alamirew T, Gudeta N, Reta MJAoTM, Parasitology. Preliminary entomological observations in a highland area of Amhara region, northern Ethiopia, with epidemic visceral leishmaniasis. 2007;101(4):367-70.

15. el-Safi SH, Peters W. Studies on the leishmaniases in the Sudan. 1. Epidemic of cutaneous leishmaniasis in Khartoum. Trans R Soc Trop Med Hyg. 1991;85(1):44-7.

16. Osman AA. Evaluation of molecular genotyping in clinical and epidemiological study of leishmaniasis in Sudan. Sci Parasitol 2011;12(3):131-7.

17. el-Hassan AM, Zijlstra EE. Leishmaniasis in Sudan. Cutaneous leishmaniasis. Trans R Soc Trop Med Hyg. 2001;95 Suppl 1(Supplement_1):S1-17.

18. Osman OF, Kager PA, Oskam L. Leishmaniasis in the Sudan: a literature review with emphasis on clinical aspects. Trop Med Int Health. 2000;5(8):553-62.

19. Jones CM, Welburn SC. Leishmaniasis Beyond East Africa. Front Vet Sci. 2021;8:618766.

20. Mohammed MA, Khalid NM, Aboud MA. Kala-azar in Darfur: Evidence for indigenous transmission in Al-Malha Locality, North Darfur, western Sudan. Parasit Vectors. 2018;11(1):149.

21. Khalid Shamboul Musab M. A study on the transmission potential of Leishmania donovani in Rahad, Upper Atbara and Blue Nile areas: UOFK; 2012.

22. Elamin E, Guizani I, Guerbouj S, Gramiccia M, El Hassan A, Di Muccio T, et al. Identification of Leishmania donovani as a cause of cutaneous leishmaniasis in Sudan. Transactions of the Royal Society of Tropical Medicine and Hygiene. 2008;102(1):54-7.

23. Khalil EA, Zijlstra EE, Kager PA, El Hassan AM. Epidemiology and clinical manifestations of Leishmania donovani infection in two villages in an endemic area in eastern Sudan. Trop Med Int Health. 2002;7(1):35-44.

24. Osman A. Epidemiology of leishmaniasis in south Kordofan region, western Sudan. J Res J Med Scien. 2011;5(2):108-11. 
25. Ebrahim NAA. Occurrence of Visceral Leishmaniasis and its Determinants in North Darfur State, Sudan (2013): University of Gezira; 2016.

26. Khalil EA, Musa AM, Elgawi SH, Meshasha A, Gamar Eldawla I, Elhassan MO, et al. Revival of a focus of visceral leishmaniasis in central Sudan. Ann Trop Med Parasitol. 2008;102(1):79-80.

27. Sharief A, Khalil E, Elmagzoub R, Omer S. Spectrum of Leishmania donovani infection in the Southwest of Sudan: a rapid epidemiological mapping. J Annals of Systems Biology. 2019;2(1):008-11.

28. Republic of Sudan Federal Ministry of Health. MANUAL FOR THE DIAGNOSIS AND TREATMENT OF LEISHMANIASIS. In: (NTDs) NTDD, editor. First ed: Federal Ministry of Health

2014. p. 49.

29. Organization WH. Framework for action on cutaneous leishmaniasis in the Eastern Mediterranean Region 2014-2018. 2014 2014. Report No.: ISBN: 978-92-9021-944-6.

30. Ali M. Epidemiology of Visceral leishmaniasis among the Populationat El Howata Town: UOFK; 2007.

31. Collis S, El-Safi S, Atia AA, Bhattacharyya T, Hammad A, Den Boer M, et al. Epidemiological and molecular investigation of resurgent cutaneous leishmaniasis in Sudan. Int J Infect Dis. 2019;88:14-20.

\section{Tables}

Table 1: Gender distribution of different patients infected with leishmaniasis classified by year

\begin{tabular}{|lllll|}
\hline Years & Female\% & Male\% & Total\% & P. value \\
\hline 2016 & $244(1.85 \%)$ & $405(3.37 \%)$ & $649(2.57 \%)$ & 0.2277 \\
\hline 2017 & $780(3.99 \%)$ & $1322(7.99 \%)$ & $2102(5.83 \%)$ & 0.0002 \\
\hline 2018 & $621(3.45 \%)$ & $1142(7.49 \%)$ & $1763(5.3 \%)$ & 0.0002 \\
\hline 2019 & $409(2.36 \%)$ & $941(5.83 \%)$ & $1350(4.03 \%)$ & 0.0015 \\
\hline 2020 & $420(2.12 \%)$ & $844(5.77 \%)$ & $1264(3.67 \%)$ & 0.0008 \\
\hline Total & $\mathbf{2 4 7 4 ( 2 . 8 2 \% )}$ & $\mathbf{4 6 5 4 ( 6 . 2 4 \% )}$ & $\mathbf{7 1 2 8 ( 4 . 3 9 \% )}$ & 0.0001 \\
\hline
\end{tabular}

Table2: Age and gender distribution of patients infected with leishmaniasis 


\begin{tabular}{|lllll|}
\hline Age group & Female\% & Male\% & Total\% & P-value \\
\hline < 1 year & 2.22 & 5.05 & 3.52 & 0.0001 \\
\hline 1-4 year & 3.93 & 4.5 & 4.19 & 0.2523 \\
\hline 5-14 year & 5.47 & 7.89 & 6.57 & 0.0001 \\
\hline 15-44 year & 5.63 & 7.68 & 6.58 & 0.0001 \\
\hline 45-64 year & 2.81 & 4.42 & 3.55 & 0.0012 \\
\hline $\mathbf{2 6 5}$ year & 1.73 & 2.2 & 1.95 & 0.3452 \\
\hline
\end{tabular}

Table 3. Comparing the sex-wise proportion of human leishmaniosis reported in each age group

\begin{tabular}{|c|c|c|c|c|c|c|c|}
\hline \multirow[t]{2}{*}{ Year } & Sex & \multicolumn{6}{|c|}{ Age group } \\
\hline & Females & $<1 \%$ & $1-4 \%$ & $5-14 \%$ & $15-44 \%$ & $45-64 \%$ & $\geq 65 \%$ \\
\hline 2016 & & 1.19 & 2.66 & 4.52 & 3.51 & 1.85 & 1.06 \\
\hline 2017 & & 2.16 & 1.8 & 6 & 4.97 & 2.47 & 2.01 \\
\hline 2018 & & 1.44 & 3.35 & 4.97 & 5.55 & 2.39 & 1.55 \\
\hline 2019 & & 3.54 & 3.9 & 5.54 & 6.81 & 2.98 & 1.77 \\
\hline 2020 & & 2.51 & 4.83 & 5.98 & 6.73 & 4.04 & 2.03 \\
\hline Total & & 2.22 & 3.93 & 5.47 & 5.63 & 2.81 & 1.73 \\
\hline 2016 & Males & 0.92 & 3.81 & 6.59 & 5.2 & 2.3 & 1.19 \\
\hline 2017 & & 2.06 & 5.26 & 8.3 & 6.9 & 3.7 & 2.35 \\
\hline 2018 & & 3.26 & 3.69 & 7.64 & 8.5 & 3.81 & 2.08 \\
\hline 2019 & & 4.64 & 3.75 & 6.9 & 7.2 & 5.08 & 2.12 \\
\hline 2020 & & 14.11 & 5.9 & 9.84 & 10.23 & 6.84 & 3.14 \\
\hline Total & & 5.05 & 4.5 & 7.89 & 7.68 & 4.42 & 2.2 \\
\hline
\end{tabular}

Figures 


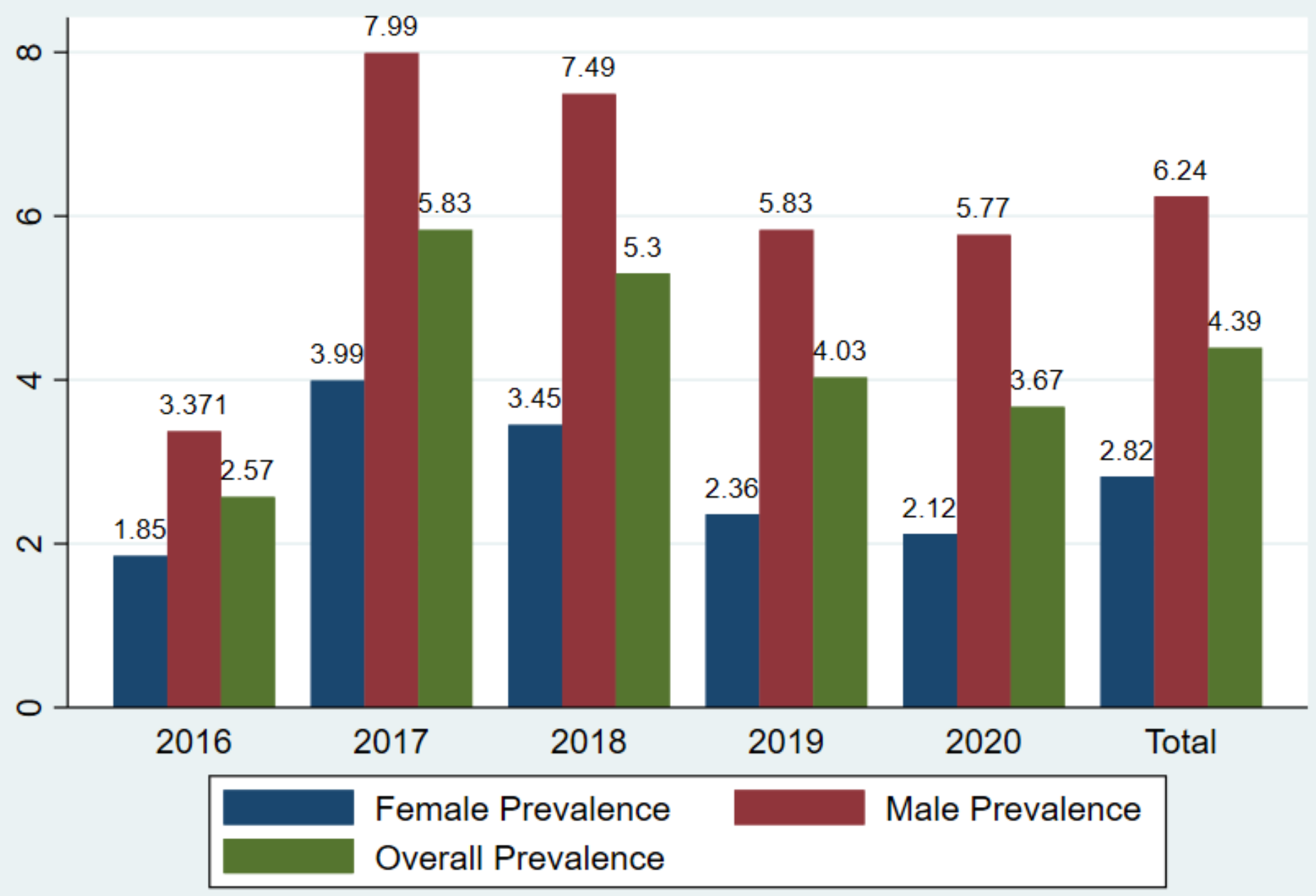

Leishmaniasis prevalence in West Kordofan state- Sudan

Figure 1

Prevalence of leishmaniasis during 2016-2020 according to gender 